\title{
Evaluation of Ecotoxicity of Nanoceria to Organisms of Different Trophic Levels
}

\author{
K. S. Vidhya Bharathi ${ }^{1}$, M. Djanaguiraman ${ }^{*}$, R. Raghu ${ }^{2}$, P. Jeyakumar ${ }^{1}$ and S. Karthikeyan ${ }^{3}$ \\ ${ }^{1}$ Department of Crop Physiology, Tamil Nadu Agricultural University, Coimbatore - 641003 \\ ${ }^{2}$ Department of Agricultural Microbiology, Tamil Nadu Agricultural University, Coimbatore - 641003 \\ ${ }^{3}$ Department of Renewable Energy, Tamil Nadu Agricultural University, Coimbatore - 641003
}

\begin{abstract}
The present study was aimed at evaluation of the toxicity potential of nanoceria on phosphobacteria (Bacillus megaterium ; soil ecosystem), azolla (Anabaena azollae and microalgae ; Aquatic ecosystem) and sorghum (Sorghum bicolor (L.) Moench) pollen grain and photosystem (PS) II quantum yield (terrestrial ecosystem). The study examined the differences in toxicity among a different concentration of nanoceria to each organism and differences in toxicity among the organisms. In each toxicity experiment, the concentration of nanoceria used are $0,5,10,25,50,100,200,400$, 500 , and $1000 \mathrm{mg} \mathrm{L}^{-1}$. The result indicated that nanoceria is not toxic to soil microbes, aquatic organisms and terrestrial plants at lower concentration (up to $25 \mathrm{mg} \mathrm{L}^{-1}$ ). However, above $25 \mathrm{mg} \mathrm{L}^{-1}$ concentration, differential responses between nanoceria and organisms were observed. Higher concentration (500 and $1000 \mathrm{mg} \mathrm{L}^{-1}$ ) inhibited the growth of phosphobacteria, microalgae, and pollen germination and PS II quantum yield. The adverse effect caused by nanoceria could be associated with the concentration of nanoceria, differences in interactions with the cell with nanoceria, and oxidative damage caused by nanoceria. Among the assays, pollen germination was found to be more sensitive to the nanoceria in the medium, followed by photosystem Il quantum yield.
\end{abstract}

Key words: Azolla; Ecotoxicity; Microalgae; Nanoceria; Phosophobacteria; Pollen germination

\section{INTRODUCTION}

The nanoparticles have potential applications in several sectors like medical science, electronics and biotechnology, including agriculture, where nanotechnology is used to synthesize nano fertilizers, carriers of agrochemicals and materials to mitigate abiotic stress (Prasad et al., 2017). Research indicated that nanoparticles are involved in the alleviation of abiotic stress in sorghum [Sorghum bicolor (L.) Moench], wheat (Triticum aestivum L.), corn (Zea mays L.) (Djanaguiraman et al., 2018a, b; Jaberzadeh et al., 2013; Zaimenko et al., 2014). In general, before adopting nanomaterials for agricultural use, nanomaterials have to be screened for ethical, societal, legal issues. In addition, a robust scientific assessment of nanomaterials' benefits and drawbacks, potential environmental, health, and safety risks of nanomaterials has to be studied. In general, toxicology depends on the dose, but in the case of nanoparticle, it depends on size, number, surface activity and aggregation (Paramo et al., 2020). In metallic nanoparticles, the properties such as solubility and binding also determine the toxicity. Any functional or morphological changes in the test organism due to exposure to nanomaterial is said to be their effects; if the effects are positive and enhance growth, then the nanomaterial has a positive influence. In contrast, if the material has adverse effects on morphology, function, and growth, it is negatively influenced. The significant aftermath of the nanoparticle toxicity in most of the organism is associated with increased production of reactive oxygen species leading to loss of membrane integrity and oxidation of biomolecules (Klaine et al., 2008). When an engineered nanomaterial is released to the environment, either by natural or anthropogenic activities, the nanoparticle may be released as intact material, or it will be broken down into base compound, which is under the influence of environmental conditions and intrinsic properties of nanomaterials (Lowry et al., 2012; Nowack et al., 2012).

Studies indicated that the application of titanium oxide nanoparticle under drought stress in wheat had improved the yield, gluten and starch content (Jaberzadeh et al., 2013). Likewise, the application of analcite, a member of the zeolite group, to wheat and maize has improved the antioxidants 
and antioxidant enzyme activity, resulting in better growth (Zaimenko et al., 2014).In Arabidopsis thaliana, the zero-valent nano iron particle (nZVI) has decreased the effects of drought stress through altering stomatal movement by activating $\mathrm{H}^{+}$ATPase activity (Kim et al., 2015).

Cerium oxide nanoparticles (nanoceria) are extensively used in the electronics and automotive industry, and there is limited use in agriculture. It is not clear whether nanoceria act as a prooxidant or antioxidant molecule due to the conflicting reports on the toxicity of nanoceria. Cerium oxide nanoparticles have gained attention for exhibiting redox activities and free radical scavenging. The controlled environmental study has shown that cerium nanoparticle can alleviate the drought stress effects in sorghum through modulating antioxidant enzymes activity and oxidant production level (Djanaguiraman et al., 2018b). Foliar application of silicon nanoparticle under salinity stress to cherry tomato has improved the photosynthesis rate, mesophyll conductance, and plant water use efficiency compared with unsprayed control (Haghighi et al., 2013). Application of $\mathrm{nTiO}_{2}$ to chickpea (Cicer arietinum L.) exposed to lowtemperature stress has improved the membrane integrity in both tolerant and susceptible genotypes (Mohammadi et al., 2013). Foliar application of copper nanoparticles against the Fusarium sp. was effective than the commercial ones (Brahmanwade et al., 2015). This unprecedented growth in the production and utilization of nanoparticles creates concerns on the safety of the environment and organisms being exposed. Hence it is mandatory that whenever a nanoparticle is developed, it should be subjected to toxicity assays. Nanoceria has been considered as one type of emerging contaminants that pose great potential risks to the environment and human health. The effects of nanoceria on soil microbes, aquatic organisms and terrestrial organisms associated with agriculture has not been studied in detail.

Therefore, we conducted an experiment to understand the toxicity effects of nanoceria on azolla, microalgae, phosphobacteria, seed germination, photosystem (PS) II quantum yield, and pollen germination. We aim (i) to examine whether there are differences in toxicity among a different concentration of nanoceria to each organism and (ii) whether for the same nanoparticle, there are significant differences in toxicity among the organisms.

\section{MATERIAL AND METHODS}

\section{Synthesis of Nanoceria}

Nanoceria was synthesized as detailed by Ketzial and Nesaraj (2011) using cerium (III) nitrate as a precursor. The cerium oxide nanoparticle synthesized was $<25 \mathrm{~nm}$ in size and rod-shaped (Djanaguiraman et al., 2018b).

\section{Evaluation of nanoceria toxicity on various organisms}

\section{Phosphobacteria}

Phosphobacteria (Bacillus megaterium) is a phosphate solubilizing organism and dwells in the rhizosphere of the plant. Phosphobacteria solubilizes immobile insoluble soil inorganic phosphates like $\mathrm{Ca}_{3}\left(\mathrm{PO}_{4}\right)_{2}, \mathrm{FePO}_{4}$, and $\mathrm{AlPO}_{4}$, through the production of organic acids, siderophores, and hydroxyl ions into mobile phosphate ions and helps in the uptake of phosphate by the plants. Phosphobacteria was subcultured in Luria-Bertani (LB) broth in Erlenmeyer flask under aseptic condition and incubated for 24 $\mathrm{h}$ in the shaker cum incubator at a temperature of $34{ }^{\circ} \mathrm{C}$ at $200 \mathrm{rpm}$. The LB broth consists of tryptone $10 \mathrm{~g} \mathrm{~L}^{-1}$, yeast extract $5 \mathrm{~g} \mathrm{~L}^{-1}$, sodium chloride $10 \mathrm{~g} \mathrm{~L}^{-1}$ and 1.5 per cent agar for solidifying the medium. LB medium with different concentration of nanoceria $(0,5,10,25,50,100,200,400,500$ and $1000 \mathrm{mg}$ $\mathrm{L}^{-1}$ ) was prepared by adding the required quantity of nanoceria. After the addition of the nanoceria, the medium was sonicated for $10 \mathrm{~min}$ and autoclaved at $121^{\circ} \mathrm{C}$ for $20 \mathrm{~min}$ and $15 \mathrm{lbs} \mathrm{sq} \mathrm{inch}^{-1}$ pressure. The medium was then plated and kept undisturbed under aseptic condition. The subculture having an optical density of 0.1 was used for inoculation. The subculture was inoculated on the plates with a dilution factor of $10^{-4}$ concentration, and the inoculation was done by smearing on the plates with an L-rod. Then the plates were wrapped and kept in an incubator for a duration of $24 \mathrm{~h}$. After incubation, the plates were counted for colony forming units (CFU) per plate to determine the effect of different concentrations of nanocerium on phosphobacteria.

\section{Azolla}

Azolla, a unique freshwater fern, symbiotically lives with the microscopic filamentous cyanobacteria called Anabaena azollae, which fixes the atmospheric nitrogen. In contrast, azolla provides the space for the survival of the bacteria. The azolla ferns were procured from the Department of Rice, Tamil Nadu Agricultural University, Coimbatore. In the present experiment azolla was grown in IRRI 2 medium. The medium consists of macronutrients such as $\mathrm{CaCl}_{2} .2 \mathrm{H}_{2} \mathrm{O} 40 \mu \mathrm{M}, \mathrm{MgSO}_{4} .7 \mathrm{H}_{2} \mathrm{O} 40 \mu \mathrm{M}, \mathrm{K}_{2} \mathrm{SO}_{4} 40$ $\mu \mathrm{M}, \mathrm{NaH}_{2} \mathrm{PO}_{4} \cdot \mathrm{H}_{2} \mathrm{O} 20 \mu \mathrm{M}$ and micronutrients such as $\mathrm{CuSO}_{4} .5 \mathrm{H}_{2} \mathrm{O} 0.01 \mu \mathrm{M}, \mathrm{H}_{3} \mathrm{BO}_{3} \mathrm{O} .2 \mu \mathrm{M}, \mathrm{Na}_{2} \mathrm{MoO}_{4} .2 \mathrm{H}_{2} \mathrm{O}$ $0.15 \mu \mathrm{M}, \mathrm{ZnSO}_{4} .7 \mathrm{H}_{2} \mathrm{O} 0.01 \mu \mathrm{M}, \mathrm{CoCl}_{2} .6 \mathrm{H}_{2} \mathrm{O} 0.01 \mu \mathrm{M}$, $\mathrm{MnCl}_{2} .4 \mathrm{H}_{2} \mathrm{O} 0.5 \mu \mathrm{M}$, Fe- EDTA.Na $\mathrm{Na}_{2} 0.5 \mu \mathrm{M}$ (Periera et al., 2009).The procured ferns were kept in the medium for overnight. Then, $500 \mathrm{mg}$ of the fern was added to $50 \mathrm{~mL}$ of the medium amended with nanoceria at different concentrations $(0,5,10,25$,

$107 \mid 10-12$ | 2 
$50,100,200,400,500$ and $\left.1000 \mathrm{mg} \mathrm{L}^{-1}\right)$. The light intensity of the growth room was $300 \mu \mathrm{mol} \mathrm{m} \mathrm{m}^{-2} \mathrm{~s}^{-1}$, and the temperature was $28^{\circ} \mathrm{C}$. The experiment was conducted for $10 \mathrm{~d}$. At the end of the experiment, the ferns were collected and weighed to calculate the fresh weight. To understand the effect of nanoceria on Anabaena structure, $100 \mathrm{mg}$ of fern was collected from each treatment. The fern was placed on the microscope slide and covered with a coverslip, then gently crushed using the forceps. The ferns were damaged resulting in the exposure of Anabaena, which was viewed in Olympus microscope at 400 times magnification.

\section{Microalgae}

Chlorella sorokiniana, microalgae, is a minute photoautotrophic organism that can be used as a biofuel or processed into proteins. The microalga was grown in the controlled condition in BG-11 medium, which contained sodium carbonate and sodium bicarbonate as the nitrogen source with macro and micronutrients and $\mathrm{pH}$ adjusted to 7.5. Medium with different concentration of nanoceria $(0,5,10,25,50,100,200,400,500$ and 1000 $\mathrm{mg} \mathrm{L}^{-1}$ ) was prepared in Erlenmeyer flask and sonicated, followed by autoclaving. The algal culture (50 $\mu \mathrm{L}$ per $100 \mathrm{~mL}$ of the medium) was added to the BG-11 medium under aseptic condition. After inoculation, the microalga was maintained for $14 \mathrm{~d}$ under a controlled environment. The light intensity of the growth room was $300 \mu \mathrm{mol} \mathrm{m} \mathrm{m}^{-2} \mathrm{~s}^{-1}$, and the temperature was $28^{\circ} \mathrm{C}$. After the expiry of the experiment, the algae were harvested by centrifugation at $3000 \mathrm{rpm}$ and dried in an oven, maintained at $50{ }^{\circ} \mathrm{C}$ for arriving dry weight.

\section{Sorghum seed germination}

The sorghum seeds cv. Co (S) 30 was purchased from the Department of Millets, Tamil Nadu Agricultural University, Coimbatore. The seeds were surface sterilized with $0.5 \%(\mathrm{v} / \mathrm{v})$ sodium hypochlorite solution for $10 \mathrm{~min}$, followed by water wash for three times. Then, the seeds were placed in a Petri dish lined with filter paper. For each Petri dish, 25 seeds were kept. Nanoceria at different concentrations $(0,5,10,25,50,100,200,400$, 500 and $1000 \mathrm{mg} \mathrm{L}^{-1}$ ) was prepared by adding the required quantity of nanoceria in water and Tween 80. The mixture was sonicated for $5 \mathrm{~min}$, and $5 \mathrm{~mL}$ of the solution was added every day till the completion of the experiment. After $10 \mathrm{~d}$, the number of seeds germinated, seedling shoot length, seedling root length and vigour index were observed. The emergence of the radicle was considered as criteria for germination. Vigour index is the product of germination percentage and seedling length.

\section{Photosystem (PS) II quantum yield}

A field experiment was conducted at Tamil Nadu
Agricultural University, Coimbatore, $\left(11^{\circ} \mathrm{N} ; 77^{\circ} \mathrm{E}\right.$; $426.7 \mathrm{~m} \mathrm{MSL}$ ) in a randomized block design with five replications. The sorghum genotype Co (S) 30 was sown during Kharif, and the crop was maintained as per the recommended package of practices. At the booting stage, ten plants were tagged for the foliar spray of different concentration of nanoceria $(0,5,10,25,50,100,200,400,500$, and 1000 $\left.\mathrm{mg} \mathrm{L}^{-1}\right)$. Nanoceria was sprayed in the evening, and the PS II quantum yield was recorded in the following day between $10 \mathrm{AM}$ and $11 \mathrm{AM}$. The PS II quantum yield was recorded continuously for three days. Chlorophyll a fluorescence parameter was measured using a modulated fluorometer (0S5p+, OptiSciences, Hudson, $\mathrm{NH}$ ) in tagged plants as explained by Djanaguiraman et al. (2013).

\section{Pollen germination}

In the field experiment, the primary panicle was tagged in 100 plants at the booting stage. These plants were not sprayed with any chemical. At anthesis, 5-10 florets were collected from tagged panicles, and the pollen grains were squeezed from the anthers by tweezers and placed on clean slides. In-vitro pollen germination was assessed by germinating the pollen in a medium containing $150 \mathrm{mg} \mathrm{H} \mathrm{BO}_{3}, 500 \mathrm{mg} \mathrm{Ca}\left(\mathrm{NO}_{3}\right)_{2} \cdot 4 \mathrm{H}_{2} \mathrm{O}, 200 \mathrm{mg}$

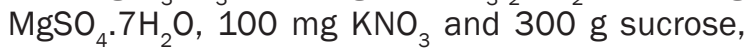
dissolved in $1 \mathrm{~L}$ of deionized water to which 15 $\mathrm{g}$ of agar per litre and different concentration of nanoceria $(0,5,10,25,50,100,200,400,500$, and $\left.1000 \mathrm{mg} \mathrm{L}^{-1}\right)$ were added. The contents were slowly heated on a hotplate until the agar dissolves and forms a clear solution. Collection of pollen and dusting on the medium was done as detailed by Djanaguiraman et al. (2004).

\section{STATISTICAL ANALYSES}

The data were analyzed using SAS program. All the toxicity experiment of the nanoceria was conducted in a completely randomized design except the field experiment. Each experiment had at least four independent replications. Observations were analyzed using the PROC GLM procedure of SAS. The standard error was shown as an estimate of variability and means of various variables were separated for significance by the LSD test at a probability level of 0.05 .

\section{RESULT AND DISCUSSION}

To increase food production to feed the evergrowing population, adopting new technologies like nanotechnology in agriculture is mandatory (Anjum et al., 2013). However, the safety of the nanomaterial to the ecosystem is of high priority. In the present study, the toxicity of nanoceria was studied. The major findings from this study are (i) inhibition of sorghum photosystem II photochemistry 
and pollen germination from $50 \mathrm{mg} \mathrm{L}^{-1}$ of nanoceria, (ii) comparing azolla and microalgae growth, azolla growth was not inhibited by nanoceria; however, the growth of microalgae was inhibited from $100 \mathrm{mg}$ $\mathrm{L}^{-1}$ of nanoceria, (iii) there is no inhibition of seed germination due to nanoceria treatment; however, the seedling vigour was decreased from $50 \mathrm{mg} \mathrm{L}^{-1}$ of nanoceria, and (iii) the growth of phosphobacteria was inhibited at higher concentration of nanoceria.
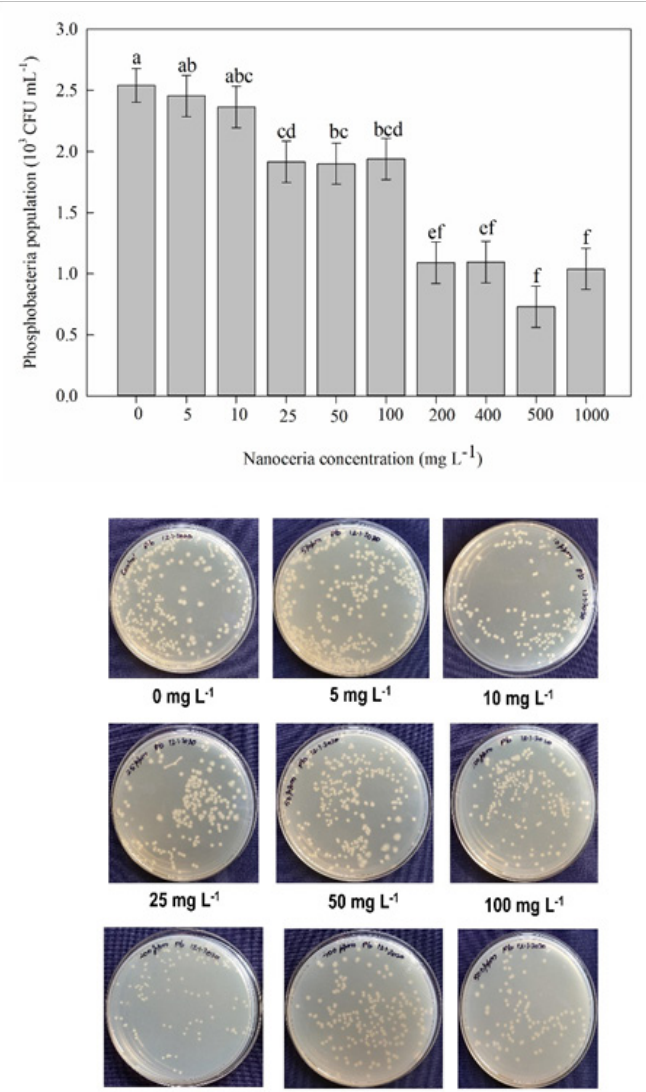

$200 \mathrm{mg} \mathrm{L}^{-1}$
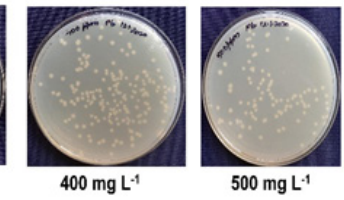

$500 \mathrm{mg} \mathrm{L}^{-1}$

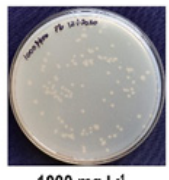

$1000 \mathrm{mg} \mathrm{L}^{-1}$

Figure 1. Phosphobacteria population dynamics as influenced by nanoceria at different concentration $\left[10^{3}\right.$ colony forming units (CFU) $\mathrm{mL}^{-1}$ ]

\section{Impact of nanoceria on phosphobacteria growth}

The effect of nanoceria on phosphobacteria growth was assessed by counting colony-forming units (CFU), and there were significant differences among the treatments (Fig. 1). The result indicated that increasing the concentration of nanoceria on the growth medium decreased the colony-forming units and a severe decrease was observed from $200 \mathrm{mg} \mathrm{L}^{-1}$ (Fig. 1). The decrease in the number of colonies may be associated with antimicrobial activity from $200 \mathrm{mg} \mathrm{L}^{-1}$ concentration (Kuang et al., 2011; Krishnan et al., 2013).

\section{Impact of nanoceria on dry biomass of azolla and microalgae}

There were significant $(P<0.01)$ differences among the nanoceria concentration for dry biomass of azolla and microalgae (Fig. 2 and 3a). The azolla and microalgae dry biomass were significantly decreased from $200 \mathrm{mg} \mathrm{L}^{-1}$ to $1000 \mathrm{mg} \mathrm{L}^{-1}$ of nanoceria (Fig. 2 and 3a). Knowing the effects of size, surface charges and chemical reactivity of nanoceria, it is possible to predict that at higher concentrations, nanoceria may induce the production of reactive oxygen species (Auffan et al., 2010).

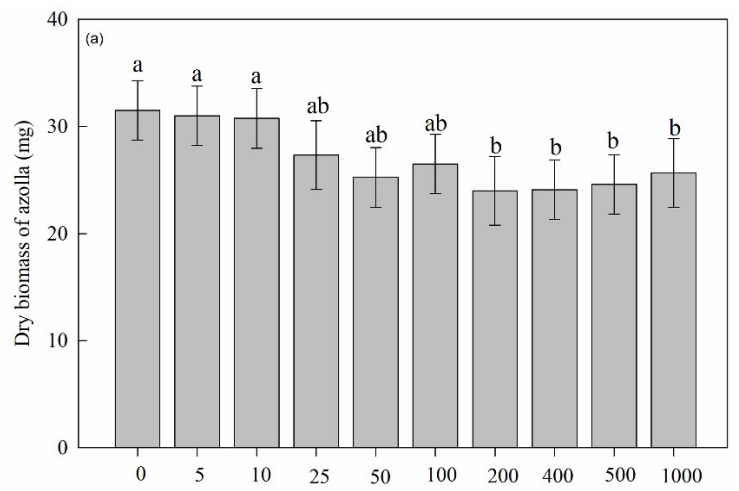

b

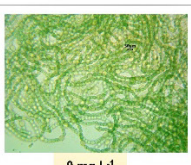

$0 \mathrm{mg} \mathrm{L}^{-1}$

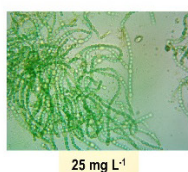

$25 \mathrm{mg} \mathrm{L}$

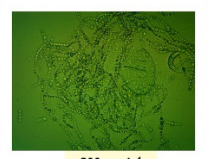

$200 \mathrm{mg} \mathrm{L} \cdot 1$

Nanoceria concentration $\left(\mathrm{mg} \mathrm{L}^{-1}\right)$
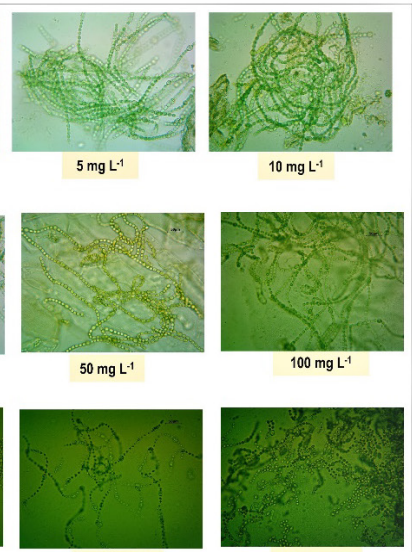

$400 \mathrm{mg}$ L-1
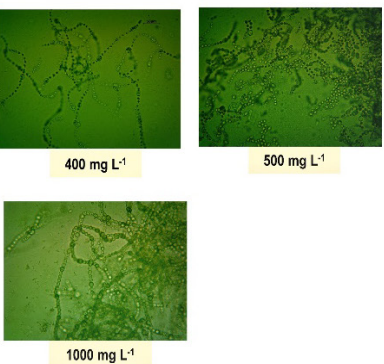

Figure 2. Effect of different concentration of nanoceria on (a) dry biomass of azolla $(\mathrm{mg})$ and $(\mathrm{b})$ structure of anabaena

The structure of Anabaena was significantly altered due to exposure to nanoceria (Fig. 2b). Anabaena, a nitrogen-fixing blue green algae, forms symbiotic relationship with azolla. Anabaena forms heterocysts and vegetative cells, and the enzyme Ribulose-1,5-bisphosphate carboxylaseoxygenase (RuBisCo) is present in the vegetative tissue of the cyanobacteria. From (Fig. 6), it is evident that nanoceria from $100 \mathrm{mg} \mathrm{L}^{-1}$ there was a

$107 \mid 10-12$ | 4 
degeneration of vegetative tissue, which may affect the nitrogen fixation process in Anabaena ( $\mathrm{He}$ et al., 2021). Also, the heterocyst frequency reduced with $100 \mathrm{mg} \mathrm{L}^{-1}$ nanoceria concentration (Fig. 2b) and subsequently may fix low levels of atmospheric nitrogen. Heterocysts differentiate from vegetative cells of some filamentous cyanobacteria to fix nitrogen for the entire filament under toxic growth conditions (Thiel et al., 2001). Due to the electron sponge property of nanoceria under aqueous condition, the probability of adsorption of $\mathrm{O}_{2}^{-}$on reduced $\left(\mathrm{Ce}^{3+}\right)$ ceria will be higher than unreduced $\left(\mathrm{Ce}^{4+}\right)$ ceria (Choi et al., 2006), due to this property at higher concentration nanoceria can damage the vegetative cells and heterocyst through the production of reactive oxygen species (Heckert et al., 2008; Rogers et al., 2010).

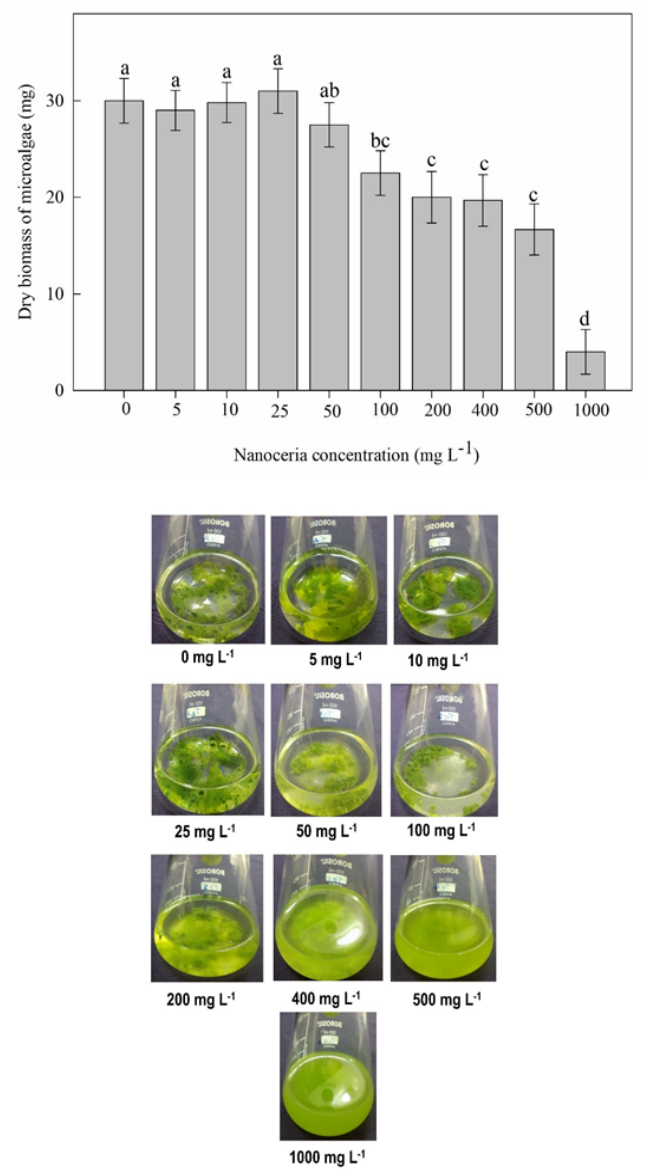

Figure.3. Effect of different concentration of nanoceria on (a) dry biomass of microalgae (mg) and (b) microalgae at different concentration of nanoceria

Impact of nanoceria on the maximum quantum efficiency of photosystem (PS) II photochemistry (Fv/Fm ratio) and in-vitro pollen germination of sorghum

The result indicated significant $(P<0.01)$ differences among the nanoceria concentrations for the maximum quantum efficiency of PS II photochemistry (Fv/Fm ratio) and in-vitro pollen germination was observed (Fig. 4 and 5). Among the various nanoceria concentrations, Fv/Fm ratio started to decrease from $50 \mathrm{mg} \mathrm{L}^{-1}$ to $1000 \mathrm{mg} \mathrm{L}^{-1}$ (Fig. 4). Exposure of nanoceria to sorghum pollen germination medium decreased the in-vitro pollen germination from $50 \mathrm{mg} \mathrm{L}^{-1}$ (Fig. 5). It is evident that increasing the concentration of nanoceria in the medium had significantly reduced the pollen germination percentage from $62 \%\left(0 \mathrm{mg} \mathrm{L}^{-1}\right)$ to 6.4 $\%$ (1000 $\mathrm{mg} \mathrm{L}^{-1}$ ) (Fig. 2).

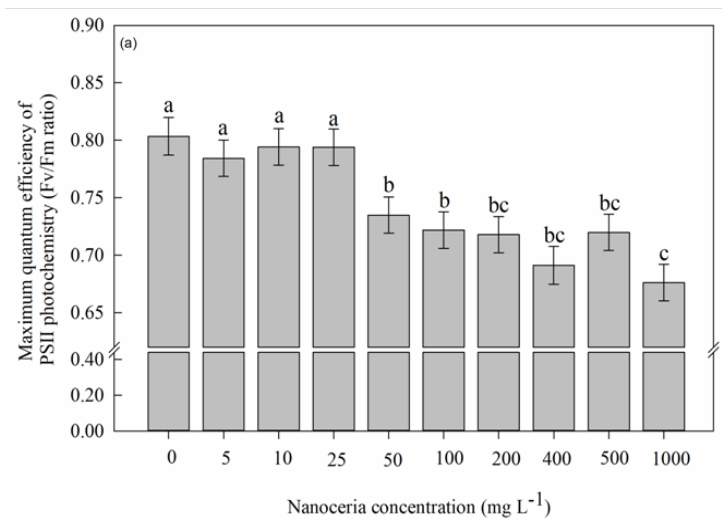

Figure 4. Effect of different concentration of nanoceria on maximum quantum efficiency of photosystem (PS) II photochemistry [Fv/Fm ratio] of sorghum

Comparing the effects of nanoceria on PS II photochemistry and pollen germination, the latter was most affected than the previous, which could be associated with the development phase of the plant (Tarafdar et al., 2012). Also, studies indicated that the method of application also causes differential toxic effects (Corredor et al., 2009). The toxicity of nanoceria at higher concentration may be associated with its morphology, size, number of nanoparticles and surface reactivity (Singh, 2016). The dual property of nanoceria i.e., no effect at low concentration and deleterious effect at higher concentration, may be related to the dual oxidation state of cerium at its surface, which can act as an oxidizer and reducer and surface adsorption property (Peng et al., 2005; Sardesai et al., 2013). Rogers et al.(2010) reported that nanoceria could produce hydroxyl radical from fatty acid. Furthermore, free $\mathrm{Ce}^{3+}$ can redox-cycling with hydrogen peroxide to generate damaging reactive oxygen species (Heckert et al., 2008). This property of nanoceria might have affected the PSIl quantum yield by inducing photoinhibition (Havaux, 1993).

\section{Impact of nanoceria on seed germination and seedling vigour}

The effects of nanoceria on seed germination and seedling vigour is presented in Fig. 7 . Overall, the impact of nanoceria on sorghum seed germination was very low. However, the effects of nanoceria 
on seedling vigour were high, as evidenced by a significant decrease in seedling vigour from $50 \mathrm{mg}$ $\mathrm{L}^{-1}$ of nanoceria. The decrease in seedling vigour is associated with decreased root length from $50 \mathrm{mg}$ $\mathrm{L}^{-1}$ to $1000 \mathrm{mg} \mathrm{L}^{-1}$ (Fig. 8), and not with germination percentage and shoot length. Seed germination percentage, root elongation, seedling biomass and the number of leaves plant ${ }^{-1}$ are considered as important physiological indices used to assess nanoparticle toxicity on plant species (Lee et al., 2010). Comparable to the present study, substantial negative effects of nanoparticle on suppression of tissue elongation were reported (Dimkpa et al., 2012; Ghosh et al., 2015). Song et al. (2013) also observed a reduction in biomass and root length in tomato due to silver nanoparticle treatment.

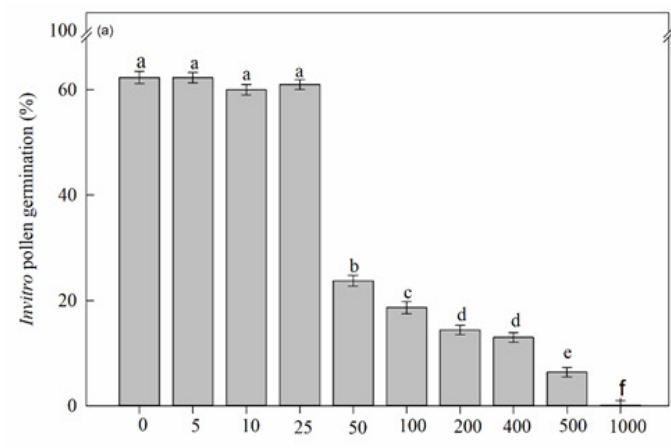

Nanoceria concentration $\left(\mathrm{mg} \mathrm{L}^{-1}\right)$

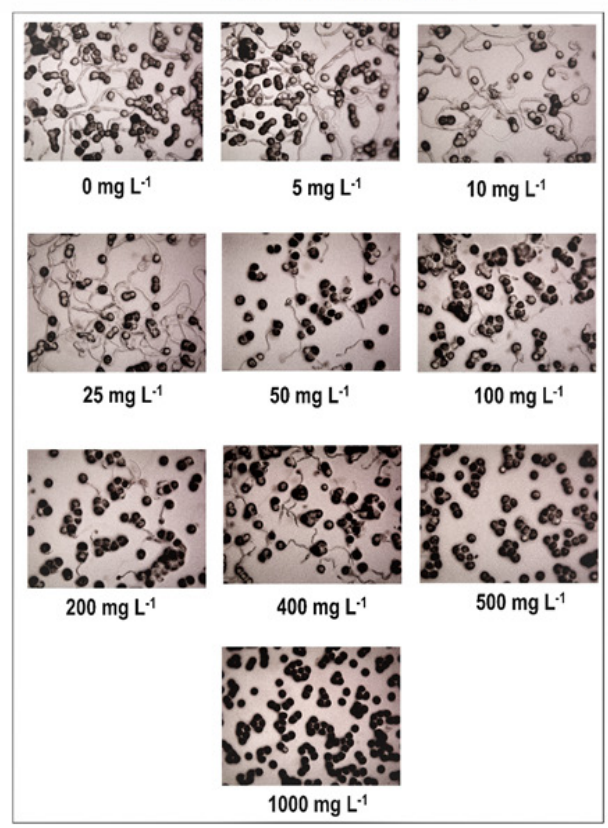

Figure 5. Effect of different concentration of nanoceria on pollen germination of sorghum

The overall mechanism associated with adverse effects of nanoceria on various processes

The present research indicated that the effects of nanoceria on different processes vary with concentration. In general, higher concentrations of nanoceria affects PS II quantum yield, pollen germination, azolla growth, Anabaena structure, microalgae growth, seedling vigour, and phosphobacteria growth (Fig. 1 to 6). The metal and metal-based nanoparticle toxicity is associated with oxidative stress (Sharma et al., 2012). The mechanism of deleterious effect may be associated with oxidative damage caused by nanoceria. Excess reactive oxygen species would cause oxidative stress, which emerges when the reactive oxygen species level exceeds the antioxidant defense mechanisms. The oxidative stress is caused by oxidants like superoxide radicals, hydrogen peroxide and lipoperoxides. During oxidative stress, the cells will undergo DNA damage, protein oxidation, electrolyte leakage, lipid peroxidation and membrane damage and eventually, cell death (Meriga et al., 2004; Sharma et al., 2012). Therefore, it is concluded that the deleterious effects of nanoceria at higher concentration may be associated with oxidative stress.

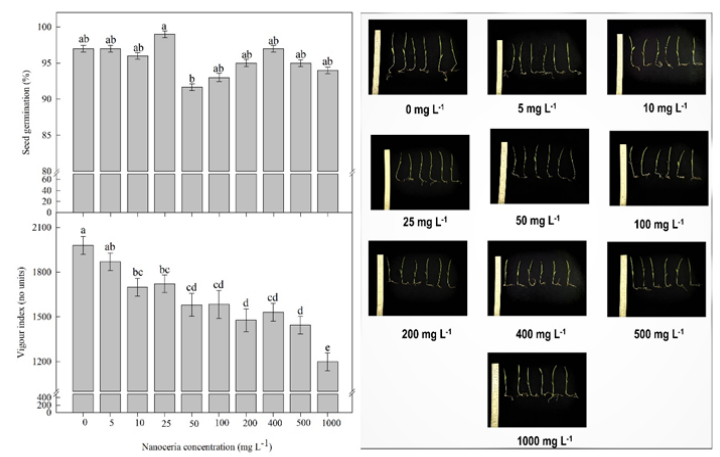

Figure 6. Effect of different concentration of nanoceria on sorghum seed germination

\section{CONCLUSIONS}

This study clearly showed that nanoceria is not toxic to terrestrial plants, aquatic organisms and soil microbes at a lower concentration, up to $25 \mathrm{mg}$ $\mathrm{L}^{-1}$. After that, differential responses were observed at different organisms and processes, which could be associated with the stage of spray or exposure methods of nanoceria to the organisms. Among the assays, pollen germination was found to be more sensitive to the nanoceria concentration in the medium, followed by photosystem II quantum yield. Therefore, this methodology can be adopted to understand the toxicity of nanomaterials on terrestrial species.

\section{REFERENCES}

Anjum, N.A., Gill, S.S., Duarte, A.C., Pereira, E. and I. Ahmad. 2013. Silver nanoparticles in soil-plant systems.J. Nano Re., 15: 1-26.

Auffan, M., Bottero, J.Y., Chaneac, C. and J. Rose. 2010. Inorganic manufactured nanoparticles: how their physicochemical properties influence their biological effects in aqueous environments. Nanomedicine.,5: 999-1007.

$107 \mid 10-12$ | 6 
Bramhanwade, K., Shende, S., Bonde, S., Gade, A. and M. Rai.2016. Fungicidal activity of copper nanoparticles against Fusarium causing crop diseases. Environ. Chem. Lett.,14(2): 229-235.

Choi, Y.M., Abernathy, H., Chen, H.T., Lin, M.C. and M. Liu. 2006. Characterization of $\mathrm{O}_{2}-\mathrm{CeO}_{2}$ interactions using in-situ Raman spectroscopy and first-principle calculations.ChemPhysChem., 7(9): 1957-1963.

Corredor, E., Testillano, P.S., Coronado, M.J., GonzalezMelendi, P., Fernandez-Pacheco, R., Marquina, C., Ibarra, M.R., De La Fuente, J.M., Rubiales, D., Perez-De-Luque, A. and R. Maria-Carmen. 2009. Nanoparticle penetration and transport in living pumpkin plants: In situ subcellular identification. BMC Plant Biol.,9: 1-11.

Dimkpa, C.O., McLean, J.E., Martineau, N., Britt, D.W., Haverkamp, R. and A. J. Anderson. 2013. Silver nanoparticles disrupt wheat (Triticum aestivum L.) growth in a sand matrix. Environ. Sci. Technol.,47: 1082-1090.

Djanaguiraman, M., Belliraj, N., Bossmann, S.H. and P. V. V. Prasad. 2018a. High-temperature stress alleviation by selenium nanoparticle treatment in grain sorghum.ACS Omega., 3(3): 2479-2491.

Djanaguiraman, M., Nair, R., Giraldo, J.P. and P. V. V. Prasad. 2018b. Cerium oxide nanoparticles decrease drought-induced oxidative damage in sorghum leading to higher photosynthesis and grain yield. ACS Omega.,3(10): 14406-14416.

Djanaguiraman, M., Prasad, P.V.V. and W. T. Schapaugh.2013. High day- or nighttime temperature alters leaf assimilation, reproductive success, and phosphatidic acid of pollen grain in soybean [Glycine max (L.) Merr.].Crop Science.,53: 1594-1604.

Djanaguiraman, M., Prasad, P.V.V.,Murugan, M.,Perumal, R. and U. K. Reddy. 2014. Physiological differences among sorghum [Sorghum bicolor (L.) Moench] genotypes under high temperature stress. Environ. Exp. Bot.,100: 43-54.

Ghosh, M., Bhadra, S., Adegoke, A., Bandyopadhyay, M. andA. Mukherjee. 2015. MWCNT uptake in Allium cepa root cells induces cytotoxic and genotoxic responses and results in DNA hyper-methylation. Mutat Res-Fund Mol M.,774: 49-58.

Haghighi, M. and M. Pessarakli. 2013. Influence of silicon and nano-silicon on salinity tolerance of cherry tomatoes (Solanum lycopersicum L.) at early growth stage.Sci. Hortic.,161: 111-117.

Havaux, M. 1993. Characterization of thermal damage to the photosynthetic electron transport system in potato leaves. Plant Sci.,94: 19-33.

He, H., Miao, R., Huang, L., Jiang, H. and Y. Cheng. 2021. Vegetative cells may perform nitrogen fixation function under nitrogen deprivation in Anabaena sp. strain PCC 7120 based on genomewide differential expression analysis. PLOS ONE.,16(3): e0248155.

Heckert, E.G., Seal, S. and W. T. Self.2008. Fentonlike reaction catalyzed by the rare earth inner transition metal cerium. Environ. Sci. Technol.,42: 5014-5019.
Jaberzadeh, A., Moaveni, P., Moghadam, H.R.T. and H. Zahedi. 2013. Influence of bulk and nanoparticles titanium foliar application on some agronomic traits, seed gluten and starch contents of wheat subjected to water deficit stress. Not Bot Horti Agrobot Cluj Napoc.,41(1): 201-207.

Ketzial, J.J. and A. S. Nesaraj. 2011. Synthesis of $\mathrm{CeO}_{2}$ NPs by chemical precipitation and the effects of a surfactant on the distribution of particles sizes. J. Ceram.,12: 74-79.

Kim, J.H., Oh, Y., Yoon, H., Hwang, I. and Y. S. Chang. 2015. Iron nanoparticle-induced activation of plasma membrane $\mathrm{H}^{+}$-ATPase promotes stomatal opening in Arabidopsis thaliana.Environ. Sci. Technol.,49: 1113-1119.

Klaine, S.J., Alvarez, P.J., Batley, G.E., Fernandes, T.F., Handy, R.D., Lyon, D.Y. and J. R. Lead. 2008. Nanomaterials in the environment: behaviour, fate, bioavailability, and effects. Environ. Toxicol. Chem.,27(9): 1825-1851.

Krishnan, A., Sreeremya, T.S., Murray, E., and S. Ghosh. 2013. One-pot synthesis of ultra-small cerium oxide nanodots exhibiting multi-colored fluorescence.J. Colloid Interface Sci.,389: 16-22.

Kuang, Y., He, X., Zhang, Z., Li, Y., Zhang, H., Ma, Y., Wu, Z. and Z. Chai. 2011.Comparison study on the antibacterial activity of nanoor bulk-cerium oxide.J.Nanosci. Nanotechnol.,11: 4103-4108.

Lowry, G.V., Gregory, K.B., Apte,S.C. and J. R. Lead.2012.Transformations of nanomaterials in the environment. Environ. Sci. Technol.,46: 68936899.

Meriga, B., Reddy, B.K., Rao, K.R., Reddy, L.A. and P. B. K. Kishor. 2004. Aluminium-induced production of oxygen radicals, lipid peroxidation and DNA damage in seedlings of rice (Oryza sativa). J. Plant Physiol.,161: 63-68.

Mohammadi, R., Maali-Amiri, R. and Abbasi. 2013. Effect of $\mathrm{TiO}_{2}$ nanoparticles on chickpea response to cold stress. Biol. Trace Elem. Res., 152(3): 403-410.

Nowack, B., Ranville, J.F., Diamond, S., Gallego-Urrea, J.A. and C. Metcalfe. 2012. Potential scenarios for nanomaterial release and subsequent alteration in the environment, Environ. Toxicol. Chem.,31: 50-59.

Paramo, L.A., Feregrino-Perez, A.A., Guevara, R., Mendoza, S. and K. Esquivel. 2020. Nanoparticles in agroindustry: applications, toxicity, challenges, and trends. J. Nanomater.,10(9): 1654.

Peng, X.J., Luan, Z.K., Zing, J., Di, Z.H., Li, Y.H. and B. H. Tian. 2005.Ceria nanoparticles supported on carbon nanotubes for the removal of arsenate from water.Mater. Lett., 59: 399-403.

Pereira, A.L. and F. Carrapico. 2009. Culture of Azolla filiculoides in artificial conditions. Plant Biosyst., 143: 431- 434.

Prasad, R., Bhattacharyya, A. and Q. D. Nguyen.2017. Nanotechnology in sustainable agriculture: recent developments, challenges, and perspectives. Front. Microbiol., 8:1014. 
Rogers, N.J., Franklin, N.M., Apte, S.C., Batley, G.E., Angel, B.M., Lead, J.R.and M. Baalousha. 2010. Physico-chemical behaviour and algal toxicity of nanoparticulate $\mathrm{CeO}_{2}$ in freshwater.J. Environ. Chem.,7: 10.

Sardesai, N. P., Daniel A. and A. Silvana. 2013. Electroanalytical evaluation of antioxidant activity of cerium oxide nanoparticles by nanoparticle collisions at microelectrodes.J. Am. Chem. Soc., 135(45): 16770-16773.

Sharma, P., Jha, A.B., Dubey, R.S. and M. Pessarakli. 2012. Reactive oxygen species, oxidative damage, and antioxidative defense mechanism in plants under stressful conditions.Am. J. Bot., 1-26.

Singh, A.K. 2016.Introduction to Nanoparticles and Nanotoxicology. Engineered Nanoparticles; Academic Press: Cambridge, MA, USA, pp. 1-18.

Song, U., Jun, H., Waldman, B., Roh, J., Kim, Y., Yi, J. andE. J. Lee. 2013. Functional analyses of nanoparticle toxicity: a comparative study of the effects of $\mathrm{TiO}_{2}$ and $\mathrm{Ag}$ on tomatoes (Lycopersicon esculentum). Ecotoxicol. Environ.Saf.,93: 60-67.

Tarafdar, J.,Xiong, Y., Wang, W.N.,Quinl, D. and P. Biswas. 2012. Standardization of size, shape and concentration of nanoparticle for plant application. Appl. Biol. Res.,14: 138-144.

Thiel, T. and B. Pratte. 2001.Effect on heterocyst differentiation of nitrogen fixation in vegetative cells of the cyanobacterium Anabaena variabilis ATCC 29413.J. Bacteriol.,183(1): 280-286.

Zaimenko, N.V., Didyk, N.P., Dzyuba, O.I., Zakrasov, O.V., Rositska, N.V. and A. V. Viter. 2014. Enhancement of drought resistance in wheat and corn by nanoparticles of natural mineral analcite. EcologiaBalkanica.,6(1): 1-10. 